Proceedings of the 2011 Winter Simulation Conference

S. Jain, R.R. Creasey, J. Himmelspach, K.P. White, and M. Fu, eds.

\title{
SUPPLY CHAIN PERFORMANCE SUSTAINABILITY THROUGH RESILIENCE FUNCTION
}

\author{
Teresa Murino \\ Elpidio Romano \\ Liberatina C. Santillo \\ University of Naples "Federico II" \\ Tecchio Square, 80 \\ Napoli, 80125, ITALY
}

\begin{abstract}
Today's business world faces challenges and pressures on an unprecedented scale. Many of these obstacles have the potential to severely affect the continuity of a manufacturing enterprise, in particular, through disruption to the wider supply chain. Indeed, it can be argued that supply chain risk is currently greater now than ever before. Resilience is one of the ways to combat disruptions in the supply chain. In this paper the behavior of a Supply chain is studied using a SD model built with Powersim. The paper describes the process of building the model and utilizes the model to demonstrate the massive improvement that resilience can bring in a manufacturing enterprise. The critical issues and strength points in a supply chain are analyzed, in particular, trying to improve their resilience, a feature that has gained even more importance in recent years.
\end{abstract}

\section{INTRODUCTION}

The catastrophic events of recent years such as the Twin Towers terrorist attack of September 11, the SARS epidemic, Hurricane Katrina and the Middle East wars have shown how the global business is vulnerable to unexpected and catastrophic events and have changed the concept of preparedness for disasters. Unfortunately, there is no way to avoid these risks, it is however noted that some organizations overcome these contingencies better than others. These organizations share a critical feature: resilience. As material science resilience represents the ability of a material to reacquire its original shape after a deformation, in the business sector resilience refers to the ability of a company to resist a seriously damaging event.

The ability of an organization to return to work after a catastrophic event depends more on the decisions taken before the event than those taken during or after. In this work the concept of resilience will be addressed at a global level since the whole supply chain is affected by such events and can derive benefit from the application of the principles presented. This work first describes supply chain risk management with a focus on models and methods used. It analyzes the causes of vulnerability of a company, focusing on the difference between risk analysis and vulnerability analysis and finding solutions to reducing these risks.

The following section is an overview of the concept of resilience with reference to relevant literature. In particular, the sensitive areas of intervention and approaches to build a resilient supply chain according to the opinions of leading experts in the field are studied. The following sections describe the model, implemented using the System Dynamics approach (Sterman 2000), and the parameters of the achieved efficiency. The simulations results are then used to provide a resilience function with the help of a design of experiments (DOE), and finally, the definition of a general resilience supply chain function is presented. 


\section{Murino, Romano, and Santillo}

\section{SUPPLY CHAIN RISK MANAGEMENT}

Supply Chain Risk Management (Juttner 2005) is a discipline of Risk Management which attempts to identify potential disruptions to continued manufacturing production and thereby commercial financial exposure (Tang and Tomlin 2008, Tang 2006). The supply chain definition focuses on the interdependences of the actors belonging to the same supply chain: sudden crisis, impacting one or more nodes inevitably creates disturbance which may destabilize the system as a whole. An element that in recent years has become increasingly important, therefore, is the safety factor. We think of terrorist incidents in recent memory that have caused some governments to invest heavily on this front, encouraging research on technologies and management tools for the security of materials, people and information flows. Although supply chain engineering methods have advanced rapidly in sophistication over the past two decades, the application of modeling and methods to explicitly consider and manage uncertainties and risks in supply chain activities is required for firms to advance to the next sophistication level. The ability to identify, assess, manage, mitigate and control the impact of disruptive events within the extended supply chain sits at the heart of comprehensive supply chain risk management.

Throughout the 1990s, many firms strived to improve their financial performance by implementing various supply chain initiatives. These initiatives were intended to increase revenue, reduce cost (e.g., supply base reduction, online sourcing including e-markets and online auctions, offshore manufacturing, Just-in-Time inventory systems, vendor-managed inventory), and reduce assets (e.g., outsourced manufacturing, Information Technology, and logistics). These initiatives can be effective in a stable environment; however, as the number of supply chain partners increases, these global supply chains become "longer" and "more complex." Long and complex global supply chains are usually slow to respond to changes, and hence, they are more vulnerable to business disruptions. According to a study conducted by Computer Sciences Corporation in 2004, $60 \%$ of the firms reported that their supply chains are vulnerable to disruptions. In the current uncertain and turbulent markets, the supply chain vulnerability has become a particularly important issue for many companies (Oke et al. 2009). The threats to the supply chain have been indeed sharpened by long and global supply chains, by products with increasingly reduced life cycles, and by volatile and unpredictable markets. A vulnerability analysis is not equivalent to a risk analysis. The latter focuses on human resources, on environmental and property impacts of an accidental event, while a vulnerability analysis is focused on the system survival. The vulnerability analysis has a wider range with respect to the risk analysis. Particularly the first concerns the way to weaken the detected threats and restart the system after an accidental event. Asbjørnslett and Rausand (1997) describe the steps to carry out a vulnerability analysis. First, an evaluation scenario is developed with the list of threats and the potential risk scenario probability. Second, a previously detected factor quantitative analysis is carried out, classifying threats and scenarios according to the criticalities in terms of impacts on human resources, environment, trade and real estates. In his work, "The Resilient Enterprise", Yossi Sheffi (2005a) analyzes the high impact/low probability disruptions. Sheffi states that in the process of creation of a resilient organization, companies must at first detect and create a priority of the risk typologies and levels they must face. Christopher (1992) gives the following definition of supply chain vulnerability: "an exposition to serious perturbations, deriving by risks inside the supply chain, as well as to risk outside the supply chain".

The supply chain risks can be classified in very different ways and by different perspectives, as shown in Figure 1. Inside the enterprise, there are a "process" and "control" risks; outside the enterprise but inside the supply chain a network risk can be identified, divided in "demand" and "supply." Finally, outside the network, there is "environmental" risk.

Among the inner risks, there are those relevant to the processes, which are sequences of added value and management activities undertaken by the company; the process risk refers to process interruptions. The controls are the engagement, the standards, the systems and the procedures used by an organization to exert its control on processes. The control risk is therefore relevant to the risk deriving from the wrong application of these standards. On the other hand, the company outer risk refers to factors relevant to 
potential or real damage with respect to the product demand, and the information and the money flow between the company and the market.

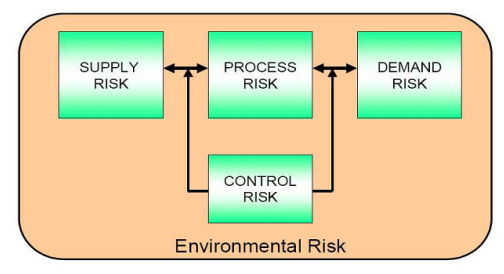

Figure 1: Risk sources in supply chain

The supply risk is the equivalent of the previous one, with the difference that it refers to the potential or real perturbation of the product/information/money flow upstream coming from the company.

There are two common measures of risk: the likelihood of the occurrence of an (undesirable) event, and the negative implications of the event. Some (undesirable) events associated with supply, process, and demand risks include: increase in supply cost, decrease in supply capability, discrepancy between forecast and actual demand, etc. There are two types of strategies for reducing supply chain risks. The first type is intended to reduce the likelihood of the occurrence of certain undesirable events, while the second type is designed to reduce the negative implications of these events.

\section{RESILIENCE IN THE SUPPLY CHAIN}

In the material sciences, resilience represents the ability of a material to reacquire its original shape after a deformation, while in the business sector, resilience refers to the ability of a company to resist a serious damaging event. The turbulent environment in which businesses operate is a main source of risk. The vulnerability of a firm increases with the volatility of demand and the globalization of the supply chain. Risk factors, in addition to acting individually on the vulnerabilities for companies operating in the supply chain, combine and influence each other (the uncertainty of such a market may be due to catastrophic events or terrorist). Basically there is a need to include in the decision-making models, not only the risks associated with traditional processes, controls, supplies and demand, but also those related to external environments in which the supply chain operates. For this reason the focus has moved from a robustnessoriented supply chain to a resilience-oriented supply chain. Robustness is the ability to remain stable with changes. The term "resilience" means the ability to return to the desired state after a major disturbance (Revetria et al. 2000).

In such a context, a company must be able to respond to the risks and vulnerabilities and rapidly returns to pre-event or even higher levels of performance. Similarly, the company must be able to manage the uncertainty of input factors while keeping the variability of output (performance levels) under control.

It is therefore a clear need to establish specific lines of research for the study and analysis of decision models for innovative companies that ensure appropriate responses to changing modern contexts. These models should integrate the following research areas:

- Supply chain management in view of resilience, robustness and security

- Risk analysis, vulnerabilities and uncertainties in the supply chain

- Prediction and analysis of market demand

- Life cycle cost

- Modeling \& Simulation

The research areas listed above are highly complementary and their integration is indeed the driving factor in the development of decision models.

Modeling \& Simulation is a technique that allows the analysis of alternative scenarios and testing of policies and models implemented. Vulnerability concept as it is applied to the production systems is defined by Asbjørnslett and Rausand (1997) as: "A strong and resilient system is able to support without 
perturbation or absorb a catastrophic failure and persist." Strong means that it is able to resist to an unexpected event and to come back in the same steady situation. Resilient means, on the other hand, able to come back in a new (often "inferior") steady situation with respect to that subsisting before the event.

The scheme in Figure 2 represents the reaction of an enterprise to a catastrophic event proposed by Sheffi (2005b). The destructive event is preceded by a "warning time" in which the company can (in some cases) predict what is going to happen and act to reduce the consequence. If it is not possible to avoid the disruption on time, it will manifest itself in all its strength after a small interval of time due to a "delayed impact". At this point the company must prepare to recover itself. Resumption materializes gradually after a "recovery time," and brings the company to a performance level that is often lower than the one before the impact.

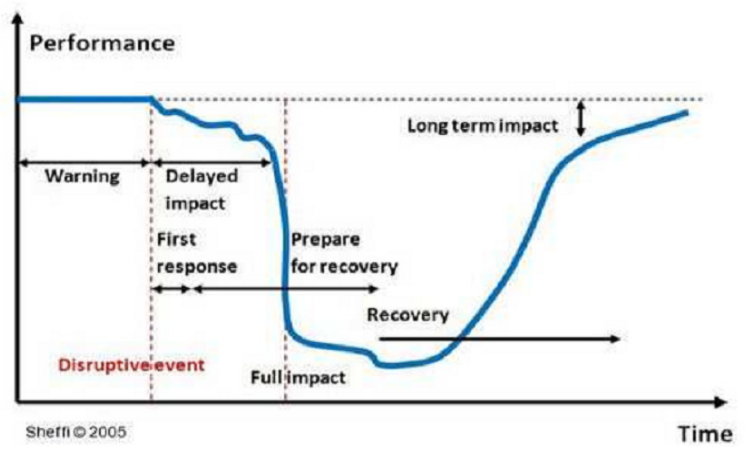

Figure 2: A damaging event profile according to Sheffi (2005b)

\subsection{Building a Resilient Supply Chain}

The risk is inevitable but can be managed (Briano et al. 2010a). There are basically two broad strategies to manage risk: an attempt to reduce the risk by reducing the consequences or the impact of increasing the supply chain responsiveness (in other words reducing the vulnerability), while the other strategies seeks to reduce the chances of occurrence, which increases its security.

Recent studies have shown as Resilience is the best way to face disruptions. According to Christopher (2004), supply chain risks can be mitigated through a systematic approach to supply chain risk management. There are 5 basic principles that allow the creation of a more resilient supply chain:

1. Supply chain understanding: mapping tools can be helpful for this.

2. Supply base strategy: Many firms have reduced the number of supplier in order to reduce production cost. It can provide a real cost reduction but this kind of strategy is dangerous in terms of resilience.

3. Supply chain collaboration: A high level of collaboration across supply chain can help to mitigate risks.

4. Agility: One of the most powerful ways to achieve resilience is agility. It's demonstrated that organizations that have focused the attention on the elimination of non-value added steps across the supply chain are more ready to respond to unexpected events. Agility is founded on two key principles, speed and visibility. Speed requires shorter end-to-end pipelines which themselves are dependent on sourcing decisions as well as internal process improvement. Visibility impacts agility in a number of ways. First, it reduces uncertainty and enables the goal of a demand driven supply chain to be achieved. Second, it reduces supply chain risk through shared information, both upstream and downstream of the firm's operations.

5. Creating a supply chain risk management (Revetria et al. 2000).

Sheffi (2005b) underlines that the company risk management shows itself under 3 forms: there are the managers dealing with the business continuity plan drawn up, there is the safety staff (badge for the access, safety codes, etc.) and finally the information technology safety function (for instance, Data backup). These 3 functions are often stand-alone and they cannot be integrated in the company strategies. 


\section{Murino, Romano, and Santillo}

The traditional definitions of business safety and continuity are only a small part of the real resilience. In particular the companies can develop the resilience mainly in three ways: increasing the redundancy, building the flexibility and changing the company culture. The first has a limited utility; the other two on the other hand are essential.

\section{THE MODEL}

A supply chain model has been developed using the commercial SD software "Powersim" (Briano et al. 2010b). The model starts from an exogenous input that simulates customer demand through a graph function. A demand profile has been set up, see Figure 3; these could be historical data from previous periods. These data have been used to forecast future customers' orders through the auxiliary "Demand planning" that take advantage of the "forecast" function that returns forecasted value of input at a time into the future. The difference between Demand planning and delayed sales forms a Gap whose average computed by the auxiliary variable "Forecasting error average" will be added to Demand planning to form the "Future forecasting."

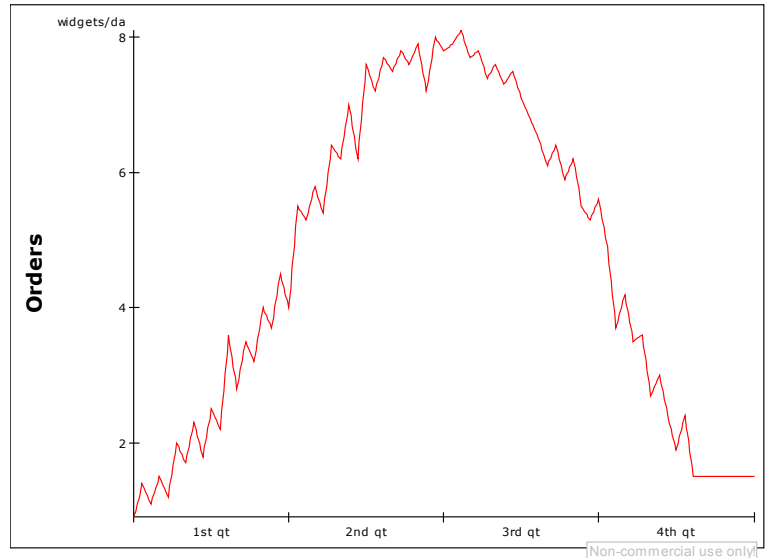

Figure 3: Orders path hypothesis

We just calculated the difference between what we expected from the market and what the market is asking; this difference along the time horizon is added to our forecast and will be very useful to fill the raw material warehouse with an appropriate level of stock.

The "Desired warehouse" auxiliary has then been built adding a constant representative of the "Safety stock" to Future forecasting auxiliary. Desired warehouse represents the raw materials level of stock that should satisfy market demand. If the level of raw materials in their warehouse (just named Raw materials) is lower than the desired warehouse, then raw materials start flowing from suppliers, otherwise the flow will be stopped until the level of stock is above the desired level.

As soon as the finished product stock level is equal to zero, the first production flow starts followed by the second with a small delay given in input. Those flows stop when finished product warehouse level exceeds the desired WIP level. Figure 4 shows daily orders not fulfilled, fulfilled backlogs, backlogs and cost, revenues and profit trends.

In this paper the supply chain model behavior is analyzed with simulation. The aim of this analysis is to note the change in the profit varying the parameters number of suppliers, amount of stock in the warehouse, variation due to disruptions, or unexpected demand peaks. The parameters mentioned are considered the most important in order to increase the resilience of the supply chain. In order to analyze how performance of a supply chain changes due to a disruption of suppliers, different supply chain characterized by 3, 2 and 1 suppliers have been analyzed.

After a disruption, a channel will be cut and the behavior of the whole system will be analyzed. The second scenario provides the reaction of the system to an unexpected peak of demand in three different 
situations characterized by a high, medium and null level of stock in the warehouse. The first scenario concerns a situation in which three different suppliers share an equal supply rate. After a disruption, the supply chain loses a supplier resulting in the behavior shown in Figure 5.
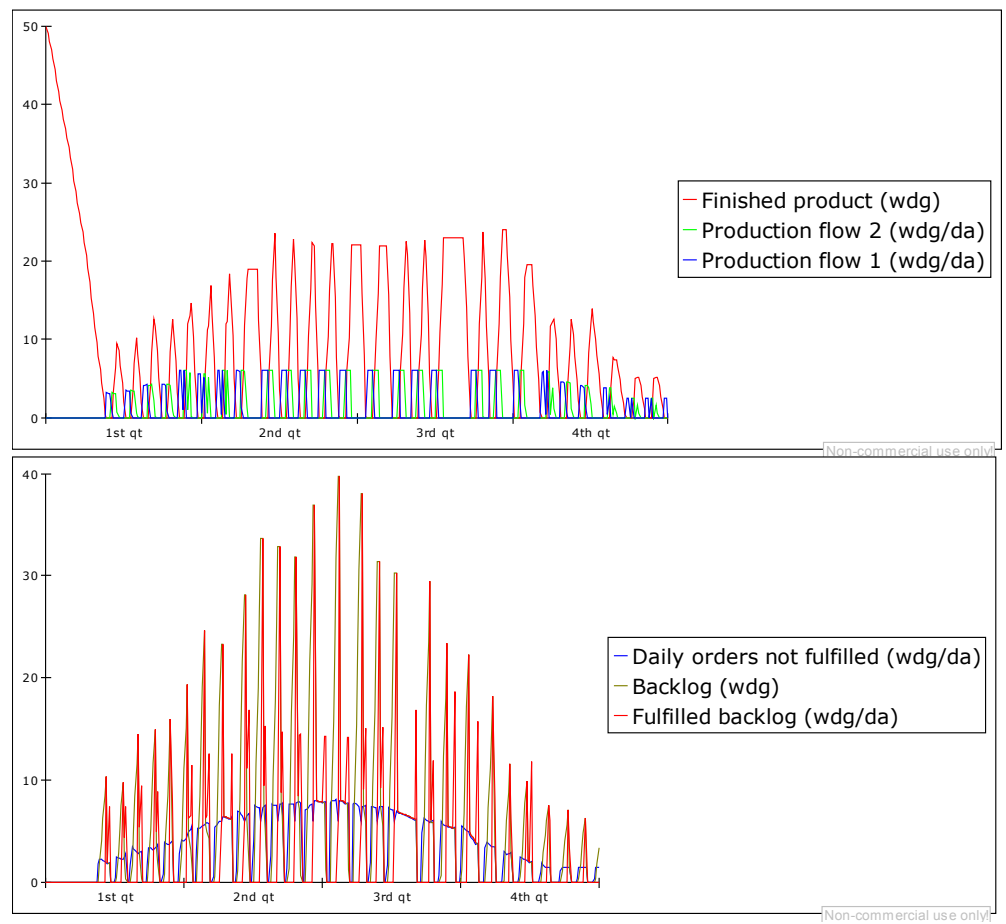

Figure 4: Production flows and backlog trends

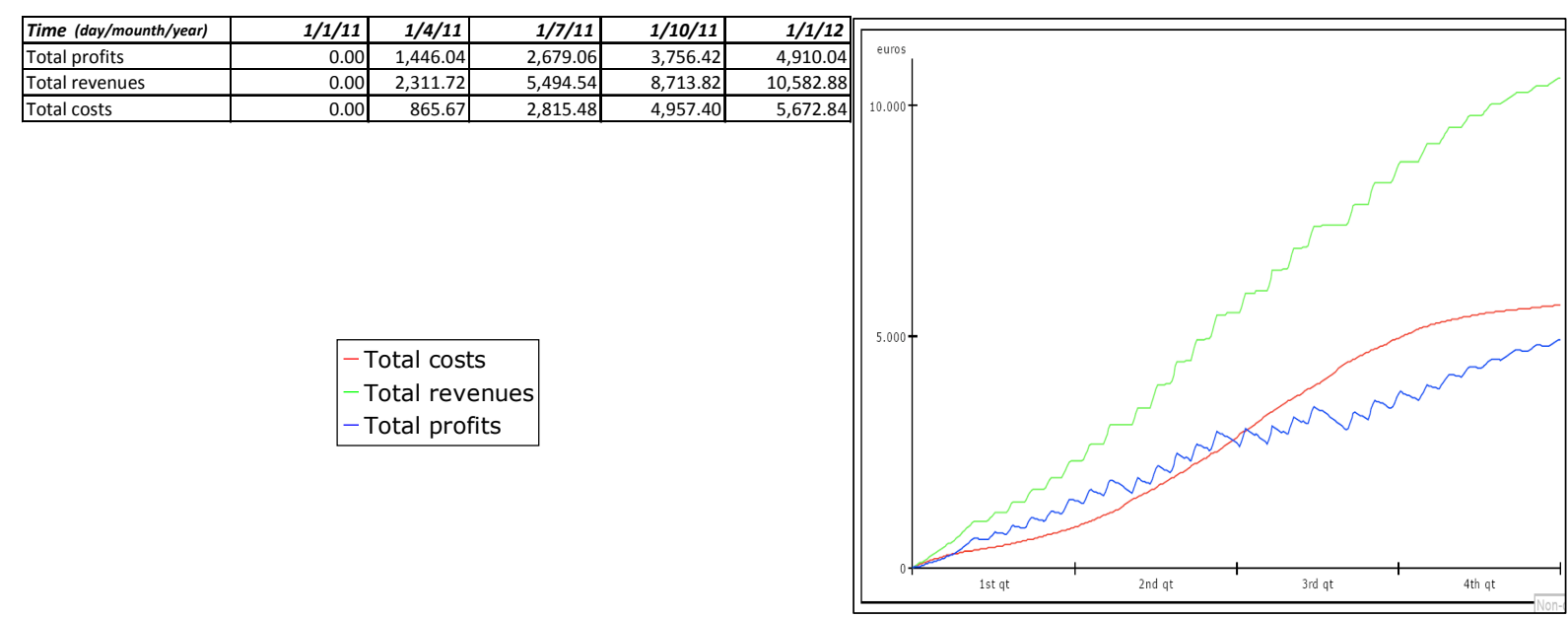

Figure 5: Losing a supply channel from three suppliers

The following is a Supply Chain model with two independent suppliers sharing at equal rate of supplying. After an unexpected event the supply chain loses a supplier resulting in the performances shown in Figure 6. Last scenario, shown in figure 7, the most catastrophic, is the loss of the only supplier.

Tables in figures 5, 6, and 7 show that profits slowly go down from first scenario to second because the supply chain appears to be resilient. The situation changes drastically in the last scenario where profits collapse due to cost increase especially due to shortage penalties. Increasing resilience in a Supply chain 
allows facing an unexpected demand variation. Next, we analyze the supply chain reaction to a demand peak (see figure 8) in different scenarios characterized by different levels of stocks.

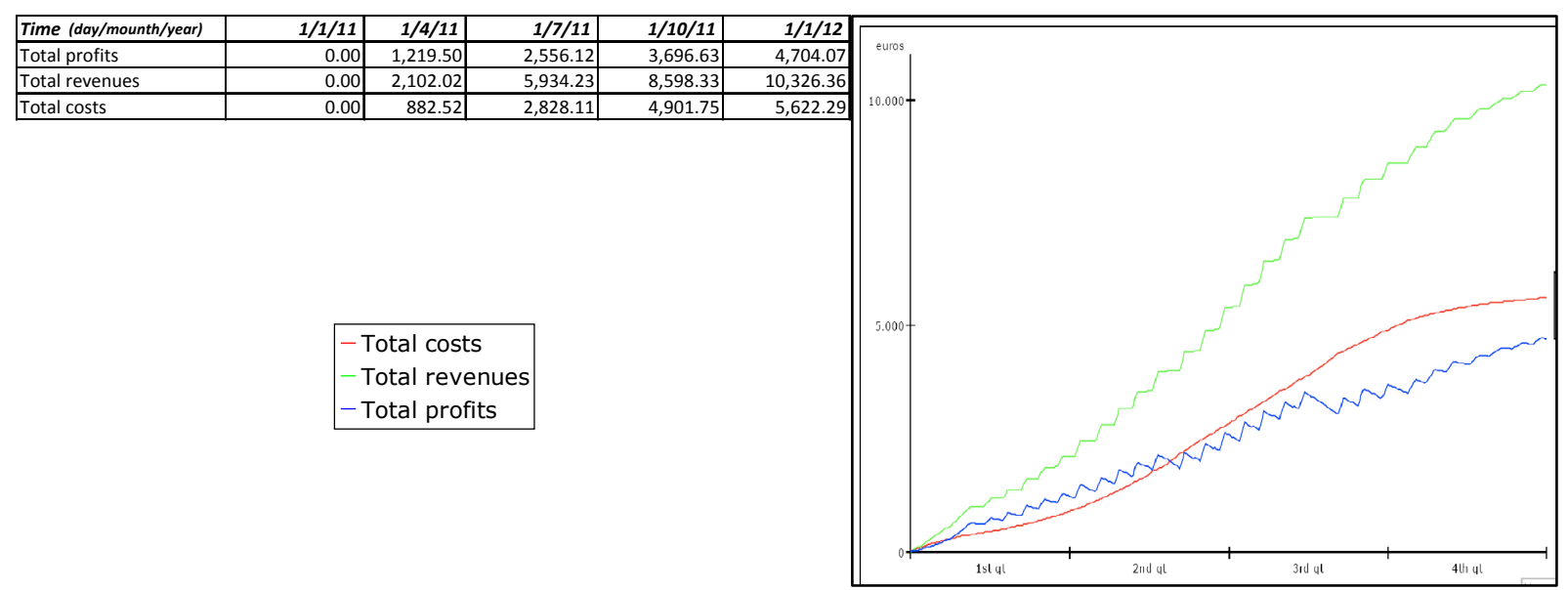

Figure 6: Losing a supply channel from two suppliers

\begin{tabular}{|l|r|r|r|r|r|r|}
\hline Time (day/mounth/year) & $\mathbf{1 / 1 / 1 1}$ & $\mathbf{1 / 4 / 1 1}$ & $\mathbf{1 / 7 / 1 1}$ & $\mathbf{1 / 1 0 / 1 1}$ & $\mathbf{1 / 1 / 1 2}$ \\
\hline Total profits & 0.00 & -12.72 & $-2,266.39$ & $-4,560.76$ & $-5,425.82$ \\
\hline Total revenues & 0.00 & $1,000.00$ & $1,000.00$ & $1,000.00$ & $1,000.00$ \\
\hline Total costs & 0.00 & $1,012.72$ & $3,266.39$ & $5,560.76$ & $6,425.82$ \\
\hline
\end{tabular}
\[ \begin{array}{l}\text { - Total costs } \\
\text { - Total revenues } \\
\text { - Total profits }\end{array} \]

Figure 7: Losing a supply channel from one supplier

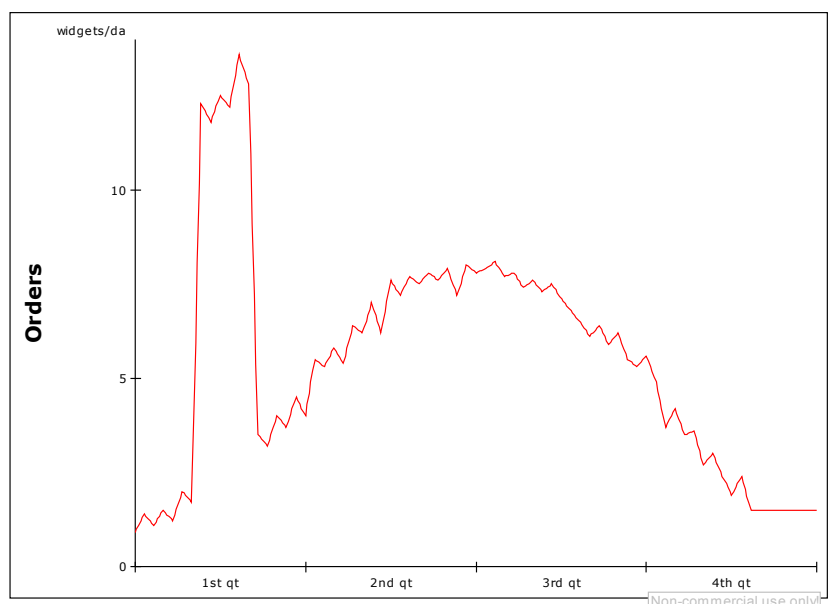

Figure 8: Demand profile with unexpected variation 
In figure 9 these results are shown. This first scenario is characterized by 20 wdg (widget) in raw materials and WIP warehouses and $40 \mathrm{wdg}$ in finished products warehouse. Last scenario doesn't include stocks, see figure 10.

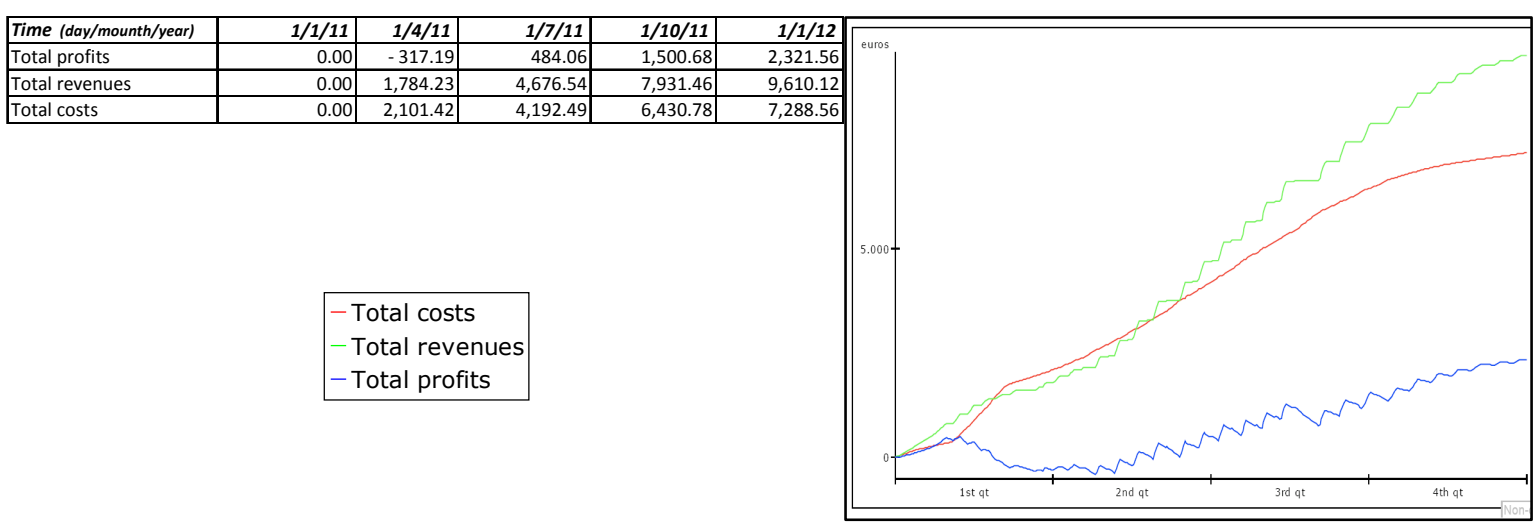

Figure 9: High stock level situation

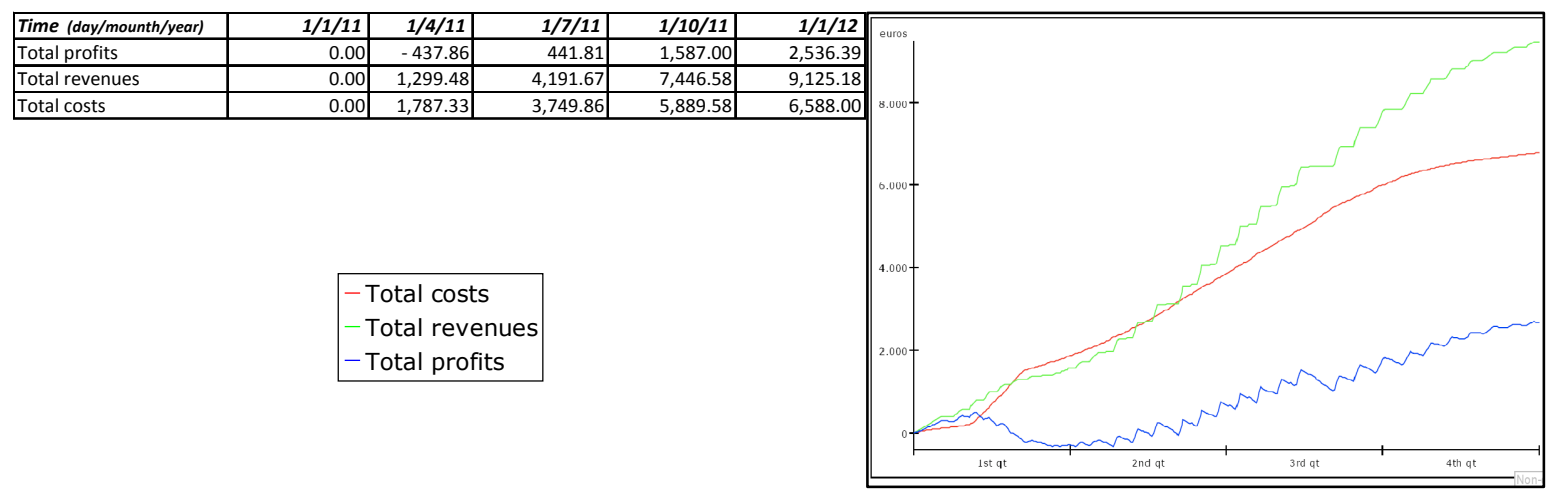

Figure 10: Null stock level situation

Unlike the previous case where the situation seemed to get better with increasing number of suppliers, here the better situation is the intermediate one. Better coverage from unexpected demand fluctuations given by a high stock level results in higher costs especially in the inventory rate.

\section{PERFORMANCE ANALYSIS}

The aim of this section is to study the responses of the model analyzed in previous paragraphs in order to determine which one is the knob that we have to move to adjust the resilience of the supply chain. A resilience function is also developed as a result of the analysis performed with a design of experiments (DOE). The perturbation in the system balance is an unexpected demand variation from the one previously forecasted: the demand under observation is shown in Figure 11.

To determine the variables that most affect the variation of resilience in the supply chain, the response of the system has been analyzed under particular operation conditions. Factors under considerations are:

- Stock level

- Number of suppliers

- Production times (speed) 


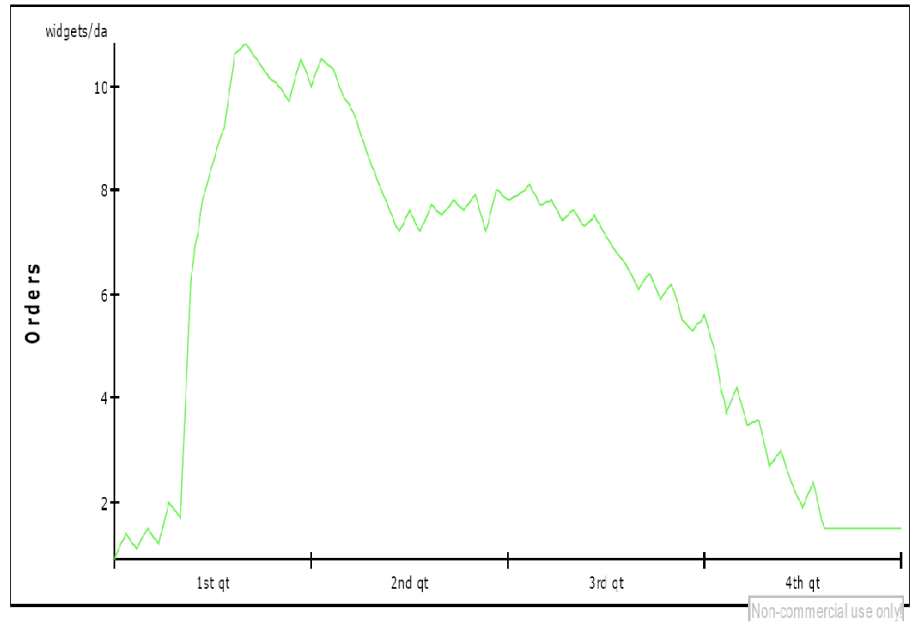

Figure 11: Demand profile

Table 1 shows the benchmarks used to exemplify normal situations, low and high performances.

Table 1: Simulation parameters

\begin{tabular}{|c|c|c|c|c|c|c|c|}
\hline & \multicolumn{2}{|c|}{ Normal } & \multicolumn{3}{|c|}{ High } & \multicolumn{2}{|c|}{ Low } \\
\hline Stock level & \begin{tabular}{l|l}
0 & 0 \\
\end{tabular} & 50 & 30 & 30 & 100 & & 0 \\
\hline no. of Suppliers & \multicolumn{2}{|l|}{1} & \multicolumn{3}{|c|}{3} & \multicolumn{2}{|c|}{1} \\
\hline Speed & $0.5 \mathrm{da}$ & $2 \mathrm{hr}$ & $0.25 \mathrm{da}$ & & $1 \mathrm{hr}$ & $1.5 \mathrm{da}$ & $4 \mathrm{hr}$ \\
\hline
\end{tabular}

The results obtained at low and high performance level varying one parameter at a time are shown in the Table 2 (the output is the enterprise profit measured in Euros):

Table 2: Model Output

\begin{tabular}{|l|r|r|}
\hline Variables & \multicolumn{1}{|c|}{+} & \multicolumn{1}{c|}{-} \\
\hline Stock level & 690.88 & $1,258.85$ \\
\hline no. of Suppliers & $2,316.76$ & $1,198.49$ \\
\hline Speed & $2,142.90$ & -652.22 \\
\hline
\end{tabular}

The interactions between model variables have been analyzed, evaluating systems response through simulations with all the possible combinations of high and low performance levels (see table 3). Data obtained from the simulation have then been used, with the help of a DOE (design of experiments), to evaluate interactions in model variables and their importance in order to vary supply chain resilience.

Table 3: Model Output with all possible variable combination

\begin{tabular}{|c|c|c|r|}
\hline Stock level & no. of Suppliers & Speed & \multicolumn{1}{c|}{ OUTPUT } \\
\hline+ & + & + & $1,711.14$ \\
\hline+ & - & + & $1,567.92$ \\
\hline+ & + & - & 873.83 \\
\hline- & + & + & $2,014.45$ \\
\hline- & - & + & $1,283.36$ \\
\hline- & - & - & $-1,030.32$ \\
\hline+ & - & - & -999.93 \\
\hline- & + & - & $1,049.84$ \\
\hline
\end{tabular}


Figure 12 shows the level of correlation between model variables. As we can note, only $C$ variable (speed), has a strong effect on the output result. To a lesser extent, $B$ variable (number of suppliers) and $B-C$ interaction represent important variables of the model. Variables with low interaction effects include the variable $A$ (stock level) and the combined variation of $A-C$. Figure 13 presents the interaction plots.

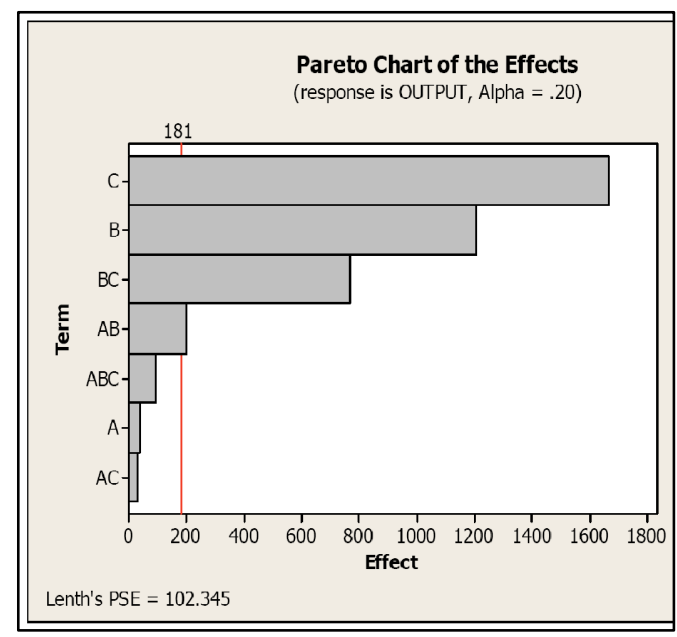

\begin{tabular}{|l|l|}
\hline Factor & Name \\
\hline A & Stock Level \\
\hline B & no. of Suppliers \\
\hline C & Speed \\
\hline
\end{tabular}

Figure 12: Pareto chart
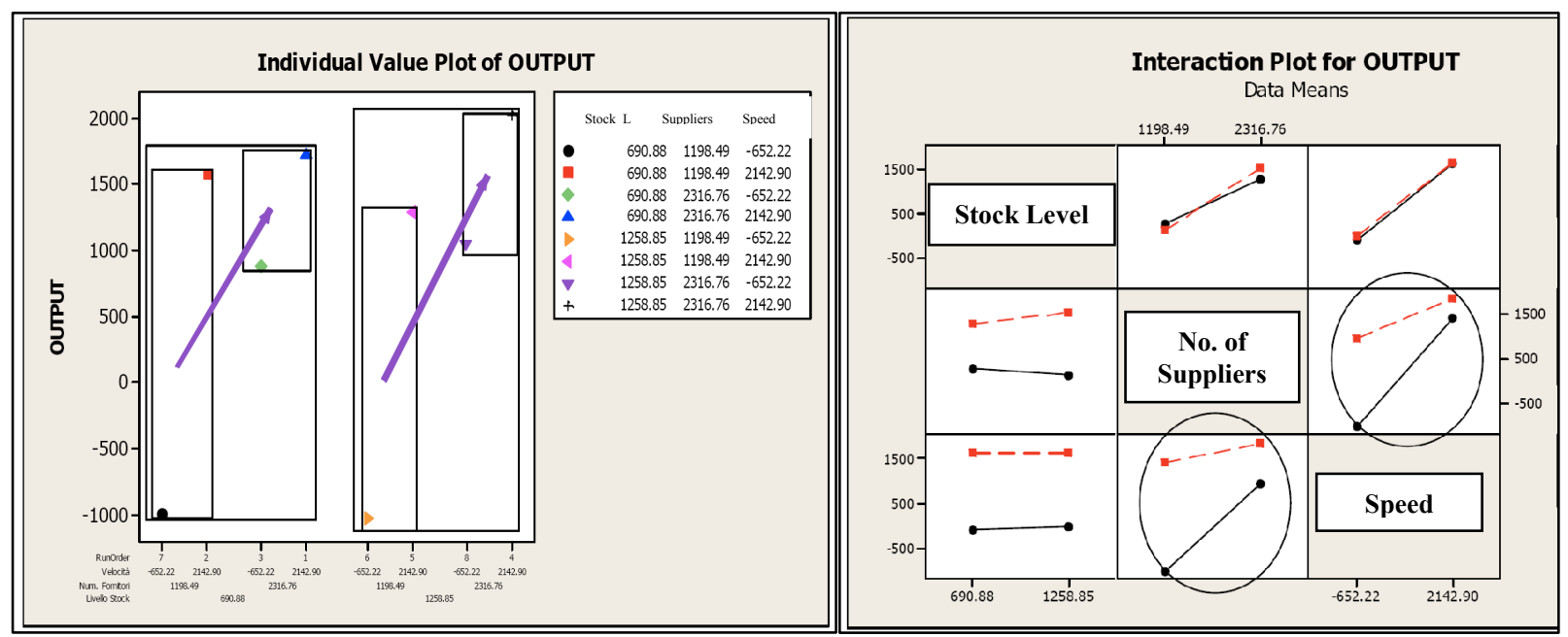

Figure 13: Individual value (left) and interaction value (right) plots

From the left plot in figure 13, it is can be seen that the output is almost the same with varying stock levels, confirming what we noted in the previous charts that the stock level variable is almost irrelevant. For a high stock level (left cluster), from a low to a high number of suppliers, we can note that the speed variable affects less; in both clusters, the first rectangle is bigger than the right one, giving a graphic evidence of what we just said. For a low stock level (right cluster), the behavior is substantially similar with the difference that, with a low number of suppliers, varying speed, the output variation is less than the previous case while the output variation is higher than the previous case with an high number of suppliers. The two-way interactions between system variables are shown in the right plot in Figure 13. As highlighted with marked circles, the most important output variations are obtained varying speed and number of suppliers. In the first case, varying speed, the output substantially changes with the two levels of number of suppliers and, in the second case, varying number of suppliers, the output changes with the 
two levels of speed. The two levels of number of suppliers and speed are almost unaffected with varying levels of stock.

The result of this work is the building of a Resilience function. Per the analysis of the results of the design of experiments, only the numbers of suppliers, the speed, and their interaction strongly affect resilience variation.

Resilience function can be defined as:

$R=\beta_{1} X_{1}+\beta_{2} X_{2}+\beta_{3} X_{3}+\beta_{12} X_{1} X_{2}+\beta_{23} X_{2} X_{3}+\beta_{13} X_{1} X_{3}$

Where $X_{1}$ variable represent speed, $X_{2}$ the number of suppliers and $X_{3}$ the level of stock. In this function only two variables and their interaction play an important role. The Stock level variable and its interaction with others variables is irrelevant in resilience variation. In resilience function, then, $\beta_{3} X_{3}, \beta_{23}$ $X_{2} X_{3}$ and $\beta_{13} X_{1} X_{3}$ terms can be considered negligible. It is also important to note how varying these two variables include different costs and behavior. Increasing or decreasing the number of suppliers depends only on supply agreements previously taken and in some situation, cutting a supply channel can be more expensive. In order to increase speed in the supply chain there is at least the need of reengineering the systems. This variable is really important to improve resilience but at a high costs of reengineering so it has to be decided whether to face this expense and be more secure in case of possible future disruptions or to spend less threatening to not overcome a future possible unexpected event.

\section{CONCLUSIONS}

In this work a methodological procedure to determine the set of decision variables that affect the resilience of the supply chain was presented. The aim is to demonstrate how to build a decision support tool that can quickly and with reasonable reliability produce effective results regarding the adaptability of the SC to sudden and unexpected internal and external disturbances through these methodological steps:

- identifying the problem

- logical links and functional definition

- process flow representation

- definition of the mathematical model

- model simulation

- decision variables determination by DOE

- a resilience analytical form design

This tool could be used both in planning and operation stages. In planning stage it can identify the extent of variation of the predominant variables that affect the resilience of the SC in order to ensure the stabilization of the same in case of disturbances. During operation, it can be used to promptly identify variables such as acting, producing, effective results for the SC on the occurrence of environmental and/or internal disruption.

The most important future development of this work is the calibration of function parameters using the model with real benchmarks. The model can be also upgraded and adapted to various supply chain with different sets of elements. It can be used to plan maintenance or to analyze system response to unexpected failures or strikes.

\section{REFERENCES}

Asbjørnslett, B. E., and M. Rausand. 1997. “Assess the Vulnerability of Your Production System.” Production Planning and Control 10:219-229.

Christopher, M. 1992. Logistics and Supply Chain Management. London: Pitman Publishing.

Briano, E., C. Caballini, P. Giribone, and R. Revetria. 2010a. "Objectives and perspectives for improving resiliency in Supply Chains.” WSEAS TRANSACTIONS on SYSTEMS 9(2):136-145. 
Briano, E., C. Caballini, P. Giribone, and R. Revetria. 2010b. "Resiliency and Vulnerability in Short Life Cycle Products' Supply Chains: a System Dynamics Model." WSEAS TRANSACTIONS on SYSTEMS 9(4):327-337.

Juttner, U. 2005. "Supply Chain Risk Management: Understanding the Business Requirements from a Practitioner Perspective." The International Journal of Logistics Management 16(1):120-141.

Oke, A., and M. Gopalakrishnan. 2009. "Managing Disruptions in Supply Chains: A Case Study of a Retail Supply Chain." International Journal of Production Economics 118(1):1 - 6.

Revetria, R., A. G. Bruzzone, R. Mosca, and S. Rapallo. 2000. "Risk Analysis in Harbour Environments Using Simulation." International Journal of Safety Science 35: $243-248$.

Revetria R., Bruzzone A.G. 2002. "Reliability Analysis by Using Simulation for Complex Automated Plants" International Journal of Simulation series ISSN 0735-9276, Volume 34 Part 4 pp. 115-119

Sheffi, Y. 2005a. "Building a Resilient Supply Chain." Harvard Business Review Supply Chain Strategy $1(8): 1-4$.

Sheffi, Y. 2005b. The Resilient Enterprise - Overcoming Vulnerability for Competitive Advantage. Boston, MA: MIT Press.

Sterman, J. D. 2000. Business Dynamics, System Thinking and Modeling for a Complex World. McGrawHill.

Tang, C. S. 2006. "Perspectives in Supply Chain Risk Management." International Journal of Production Economics 103(2): $451-488$.

Tang, C. S., and B. Tomlin. 2008. "The Power of Flexibility for Mitigating Supply Chain Risks." International Journal Production Economics 116:12 - 27.

\section{AUTHOR BIOGRAPHIES}

TERESA MURINO graduated in Mechanical Engineering, and is an assistant professor in the ING-IND 17, Industrial Plant System disciplinary group, in the Faculty of Engineering at University of Naples "Federico II." She teaches Manufacturing System Management, Goods and Services Production System, and Industrial Logistics at Engineering Faculty. She is also Professor at "Consorzio Nettuno". She is also a peer-reviewer for Elsevier Editorials, and other ISI indexed journals. Her research activities are mainly concerned about the following topics: Simulation modeling, Maintenance strategies, Supply Chain Management models, Quick Response Manufacturing, Sustainable production processes, Location-Routing and vehicle routing Problem, and Lean approach implementations. Her email address is murino@unina.it.

ELPIDIO ROMANO graduated in Transportation Engineering, and is a $\mathrm{PhD}$ in Transportation Systems and Theory. At the moment he is a contract researcher at the Department of Materials Engineering and Operations Management of the University of Naples "Federico II" Faculty of Engineering. He is a Tutor at "Uninettuno University." His research activities are mainly concerned about the following topics: Simulation modeling, Traffic and Transportation simulation and analysis, Maintenance strategies, Supply Chain Management models, Quick Response Manufacturing, Sustainable production processes, LocationRouting and vehicle routing Problem, Lean Service and Lean production implementation. He is author of several papers presented at international conferences and published in international journals of industrial engineering. His e-mail is elromano@unina.it.

LIBERATINA CARMELA SANTILLO graduated in Mechanical Engineering, and is a Full Professor in the ING-IND 17, Industrial Plant System disciplinary group, in the Faculty of Engineering at University of Naples "Federico II." She teaches Safety and Security Management, Industrial and Mechanical Plants and Industrial Logistics at Engineering Faculty. Her research activities are mainly concerned about the following topics: Safety and Security management models, Simulation modeling, Maintenance strategies, Supply Chain Management models, Quick Response Manufacturing, Sustainable production processes, Lean Service and Lean production implementation. Her email address is santillo@unina.it. 